\title{
A OUTRA FACE DO DISCURSO EM MICHEL FOUCAULT
}

\author{
Anderssieli Irion Boschetti ${ }^{1}$
}

\section{Resumo:}

O objetivo deste artigo é apresentar a aula inaugural de Michel Foucault intitulada A ordem do discurso. A pretensão central de Foucault no decorrer desse pronunciamento é introduzir novas regras metodológicas para analisar o estatuto do discurso. A hipótese foucaultiana ressalta que o discurso da realidade é controlado com o intuito de evitar a proliferação discursiva e manter a ordem para tornar os discursos institucionalizados. Desse modo, o discurso limita-se a adquirir existência efetiva somente quando submetido à procedimentos de controle discursivos, os quais expressam os rituais de exclusão que não cessam de existir nas sociedades.

Palavras chave: Coerção. Discurso. Exclusão.

\section{Abstract:}

The purpose of this article is to present the inaugural lecture class of Michel Foucault called the order of discourse. The central claim of Foucault in the course of this statement is to introduce new methodological rules for analyzing the speech status. Foucault's hypothesis points out that the discourse of reality is controlled in order to avoid the discursive proliferation and maintain order to become institutionalized discourses. Thus, the speech is limited to acquire effective existence only when submitted to discourse control procedures, which express the exclusion rituals that do not cease to exist in societies.

Key-words: Coercion. Speech. Exclusion.

Ao analisar o estatuto do discurso em sua aula nomeada $A$ ordem do discurso ${ }^{2}$, Michel Foucault elucida que, dentre os principais procedimentos de coerção discursiva destacam-se três grupos. O primeiro grupo de procedimentos se refere à limitação discursiva, a qual decorre de exclusões ocasionadas por fatores externos através de três vias: a palavra proibida, a segregação da loucura e a vontade de verdade. A primeira exclusão ocorre a partir da restrição à palavra, ou seja, o direito para falar em determinados assuntos é vedado. Devido ao

\footnotetext{
${ }^{1}$ Aluna regular do Programa de Mestrado em Filosofia da Universidade Estadual do Oeste do Paraná.

${ }^{2}$ Quando este discurso é pronunciado por Foucault em 2 de dezembro de 1970 no Collège de France, não é apenas para cumprir com as formalidades por assumir o cargo - renomeado de história do pensamento filosófico para história dos sistemas de pensamento - no lugar de Jean Hyppolite, pois Foucault aproveita a ocasião para expressar sua sincera gratidão, àquele que além de precedê-lo, contribuiu para a sua formação ao ministrar as aulas preparatórias no Liceu Henri-IV em 1945, no período de dois meses, sendo um professor exemplar que apresentou a filosofia de Hegel através de uma abordagem envolvente e cativante. "Alguns quiseram ver nessas palavras que encerravam um discurso oficial apenas o mero respeito às convenções acadêmicas: Foucault sucedia a Hypollite, e reza a tradição que o novo titular elogie seu predecessor, falecido ou aposentado. Mas Foucault dedica a Hypollite todo o final dessa aula, embora pudesse se limitar a pronunciar algumas palavras, algumas frases" (DIDIER, 1990, p. 34). Nesse sentido, no momento em que Foucault inicia este discurso, ele já evoca uma voz, fazendo menção a Jean Hyppolite, conforme a seguinte passagem: "Gostaria de perceber que no momento de falar uma voz sem nome me precedia há muito tempo [...]" (FOUCAULT, 2012a, p. 05). Do mesmo modo, ao término deste discurso, ele continua seus agradecimentos: "Penso, no entanto, que minha dívida, em grande parte, é para com Jean Hypollite" (FOUCAULT, 2012a, p. 67). Em relação a Jean Hypollite, ele não era considerado filósofo, mas adquiriu prestígio ao ser o primeiro tradutor na língua francesa da obra Fenomenologia do Espírito de Hegel.
} 
seu envolvimento com o desejo e o poder, o discurso não é utilizado apenas como modo de descrição ou expressão, mas detém uma função ativa, que incita os indivíduos a lutar pelo poder de ação: “[...] o discurso não é simplesmente aquilo que traduz as lutas ou os sistemas de dominação, mas aquilo porque, pelo que se luta, o poder do qual nós queremos apoderar" (FOUCAULT, 2012a, p. 10). A segunda exclusão é manifestada através da segregação da loucura, pois embora o louco seja reconhecido com base em suas palavras emitidas, no século XVII (período Clássico), elas são consideradas vazias de significado e são descartadas de imediato, porque não existem tentativas que propiciam o entendimento do que foi pronunciado. E quando, no século XIX (período Moderno), acredita-se que finalmente seja possível superar a dicotomia entre a razão e a loucura, pela criação de instituições e com a inserção de profissionais especializados destinados a detectar o que é dito ${ }^{3}$, nota-se que a separação ainda permanece: "[...] é sempre na manutenção da cesura que a escuta se exerce" (FOUCAULT, 2012a, p. 12-13). A terceira exclusão elucida a existência de uma vontade de verdade constituída através de um sistema histórico que conduz à vontade de saber. Conforme Foucault, os poetas gregos priorizavam o discurso verdadeiro, que incitava o respeito e o terror, sendo emitido por um representante que, através de rituais específicos, expressava a justiça direcionando aos indivíduos as suas atribuições, e, além disso, auxiliava intervindo no destino dos indivíduos, não apenas profetizando o porvir, mas oferecendo condições para efetivação do mesmo. No entanto, em breve a verdade se restringe aquilo que o discurso emite, ou seja, é analisada a partir do enunciado, resultando na dicotomia entre o discurso verdadeiro e o falso, destituindo assim o poder da mesma, pois é submetida a uma análise. Entre outros motivos, essa dicotomia surge devido a uma vontade de saber, que detém níveis técnicos que analisam os conhecimentos através dos critérios da verificação e utilidade. Desse

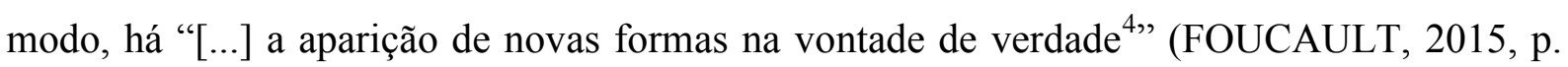

\footnotetext{
${ }^{3}$ De acordo com Foucault, há um filtro do saber, e aquilo que o louco emite não corresponde a sua situação atual (ao seu modo de pensar): "Impuseram-lhes uma língua estrangeira [...] Pelo fato de terem sido dominados, uma língua e conceitos lhe foram impostos" (FOUCAULT, 2012b, p. 104).

${ }^{4}$ Para Foucault, os dois sistemas de exclusão - a palavra proibida e a segregação da loucura - são permeados pelo contexto da vontade de verdade, que apenas ressalta o viés positivo de tais restrições e separações, "e ignoramos, em contrapartida, a vontade de verdade, como prodigiosa maquinaria destinada a excluir [...]" (FOUCAULT, 2012a, p. 19). No entanto, vários tipos de discursos são afetados “[...] pelo modo como o saber é aplicado em uma sociedade, como é valorizado, distribuído, repartido e de certo modo atribuído" (FOUCAULT, 2012a, p. 17); por exemplo, o discurso literário, somente sendo possível na medida em que expresse um discurso verdadeiro; as práticas econômicas sendo relacionadas somente ao parâmetro de riqueza e produção; o sistema penal sendo assegurado pelo direito, e posteriormente por um saber específico (psicólogos, médicos, psiquiatras).
} 
15), que foram possibilitadas pela criação de instituições, nas quais o saber adquire valoração sendo difundido com base naquilo que cada sociedade considera verdadeiro.

No segundo grupo de procedimentos de coerção discursiva, há a dominação de aparecimentos distintos através de sistemas de exclusões internos baseados na análise do próprio discurso, tais como: o princípio do comentário, o princípio de rarefação (autor), e o princípio de limitação (disciplinas). O princípio do comentário pode apresentar um desnivelamento discursivo, não sendo possível diferenciar os discursos primários, que são aqueles criadores e possibilitam os outros discursos, daqueles discursos secundários que são adaptados e repetem de outro modo o que foi dito. No entanto, embora o discurso se altere em termos de aplicação, a função do mesmo permanece: "O comentário conjura o acaso do discurso [...] para o número, a forma, a máscara, a circunstância da repetição" (FOUCAULT, 2012a, p. 25). Quanto ao princípio de rarefação, o mesmo é correlato ao anterior, na medida em que vários discursos são repassados sem a menção de autoria, mas dependendo do tipo de domínio discursivo é exigida a especificação do autor. Por exemplo, na ordenação dos discursos científicos a elucidação do autor possibilita que o discurso adquira valor de verdade no âmbito científico, embora posteriormente o nome do autor se limite a nomear as suas descobertas. No discurso literário, entretanto, o autor é questionado sobre suas obras e o sentido que ele atribuiu em cada contexto. Assim, para Foucault "o princípio do autor limita esse mesmo acaso [do comentário] pelo jogo de uma identidade que tem a forma da individualidade e do eu" (FOUCAULT, 2012a, p. 28). Em relação ao princípio de limitação, há oposições quando comparado aos anteriores - o comentário e o autor -, pois as disciplinas são organizadas sem estabelecer a nomeação de autoria específica, como também não há a repetição do que foi dito através de comentários. As disciplinas são possibilitadas por proposições novas, desde que os seus objetos sejam determinados e possam se inserir num âmbito teórico preestabelecido. Portanto, "a disciplina é um princípio de controle da produção do discurso [...]" (FOUCAULT, 2012a, p. 34). Desse modo, as proposições não são validadas apenas em decorrência do parâmetro da verdade ou erro, mas mediante outras exigências que mudam de acordo com a aquisição de novos saberes inseridos em regras, denominadas por Foucault como "polícia discursiva", que restringem os discursos pela coerção.

O último grupo de coerção discursiva visa à delimitação da função discursiva, operando através do selecionamento de indivíduos com base em quatro modos: o ritual da palavra, as sociedades do discurso, os grupos doutrinários e as apropriações sociais. O 
primeiro modo elucida os sistemas de restrição que acontecem por rituais ${ }^{5}$ que qualificam e definem a posição e a função dos indivíduos conforme o valor coercitivo requerido. $\mathrm{O}$ segundo se baseia em sociedades arcaicas em que se realizam recitações secretas que devem ser mantidas em sigilo, "[...] cuja função é conservar ou produzir discursos [...]" (FOUCAULT, 2012a, p. 37), evitando a propagação de informações. Nesse sentido, Foucault ressalta que, por um lado, o atual padrão do ato de escrever segue as exigências dessas sociedades de discurso na edição de uma obra, e que, por outro lado, existem outros discursos que são exaltados e difundidos no âmbito em que se encontram inseridos, tais como o discurso médico, o econômico ou o político. O terceiro modo ocorre em grupos doutrinários que pressupõem uma pertença prévia de acordo com os tipos de enunciados fixados, através da análise da fala de cada sujeito que pretende inserir-se no grupo, desse modo, atua unindo as classes com os mesmos interesses delimitando os critérios que os distinguem dos demais grupos. O último modo referente aos grupos doutrinários e as apropriações sociais, elucida como o discurso adquire uma difusão de caráter social, é o caso da educação, que, apesar de ser considerada liberal, também é restrita ao modo do pensar político vigente: "Todo o sistema de educação é uma maneira política de manter ou de modificar a apropriação dos discursos, com os saberes e os poderes que eles trazem consigo" (FOUCAULT, 2012a, p. 41). Perante a enunciação dessas divisões, Foucault menciona que em vários momentos se percebe a fusão de todos esses modos de seleção operando através da sujeição do discurso nos sistemas de ensino, de escrita, no judiciário e no âmbito médico.

Segundo Foucault, ligados aos procedimentos de coerção discursiva acima citados, surgem temas filosóficos que pretendem formular respostas mediante a construção de uma verdade ideal para conduzir o discurso. Esses temas, em alguns momentos, incentivam as limitações e as exclusões descritas nesses procedimentos pelo privilégio atribuído à abordagem racional imanente, a fim de direcionar o desenvolvimento discursivo e, consequentemente, destituir a sua realidade: “[...] parece que o pensamento ocidental tomou cuidado para que o discurso ocupasse o menor lugar possível entre o pensamento e a palavra" (FOUCAULT, 2012a, p. 43). As principais noções filosóficas em que Foucault ressalta essa situação são as seguintes: sujeito fundante, experiência originária e mediação universal. O primeiro tema ou noção realiza a escritura discursiva com base na intuição para desvendar e

\footnotetext{
${ }^{5}$ Os rituais podem acontecer em várias instâncias de acordo com os valores requeridos, por exemplo: "Os discursos religiosos, judiciários, terapêuticos e, em parte também, políticos, não podem ser dissociados dessa prática de um ritual que determina para os sujeitos que falam, ao mesmo tempo, propriedades singulares e papéis preestabelecidos" (FOUCAULT, 2012a, p. 37).
} 
interpretar o sentido oculto das coisas e estabelecer significações por meio de deduções: "Na sua relação com o sentido, o sujeito fundador dispõe de signos, marcas, traços, letras. Mas, para manifestá-los, não precisa passar pela instância singular do discurso" (FOUCAULT, 2012a, p. 44-45). O segundo tema apresenta uma característica semelhante, pois pressupõe uma interpretação primitiva do mundo, na qual o discurso é considerado uma leitura das coisas dispostas através da manifestação do sentido que delas emanam. O último tema prioriza um retorno à consciência de si, pelo modo como o discurso é possibilitado, ou seja, ele apenas serve como troca mediadora entre as coisas e o mundo: "O discurso nada mais é do que a reverberação de uma verdade nascendo diante de seus próprios olhos" (FOUCAULT, 2012a, p. 46). Em todos os temas filosóficos citados, de acordo com Foucault, o intento é conduzir o discurso com ênfase nos signos (ordem do significante) ao invés de abordar o contexto de sua realidade. Desse modo, o discurso da realidade não é possibilitado devido ao temor e a desordem que ele pode suscitar, na medida em que ele revela a outra face das coisas: "[...] tudo o que possa haver aí de violento, de descontínuo, de combativo, de desordem, também, e de perigoso, desse grande zumbido incessante e desordenado do discurso" (FOUCAULT, 2012a, p. 48).

Para analisar esse temor que advém do discurso, Foucault elenca quatro estratégias de método, que visam repensar a vontade de verdade para que seja possível devolver ao discurso a sua particularidade de acontecimento, desvinculando-o do monopólio dos signos: "Quatro noções devem servir, portanto, de princípio regulador para a análise [...] que se opõem termo a termo: o acontecimento à criação, a série à unidade, a regularidade à originalidade $\mathrm{e}$ a condição de possibilidade à significação" (FOUCAULT, 2012a, p. 51). A primeira estratégia é denominada de princípio de inversão, que consiste numa abordagem que detecta em qualquer positividade instituída aquilo que existe de negativo, ou seja, elucida os recortes ocasionados pela rarefação discursiva. A segunda estratégia é correlata a anterior, sendo nomeado como princípio de descontinuidade, que atua trazendo a superfície os discursos ilimitados que estavam camuflados pela rarefação e caracterizá-los como práticas descontínuas, que podem ou não estabelecer relações entre si. A terceira estratégia decorre do princípio de especificidade que possibilita que os acontecimentos discursivos possuam sua regularidade, por meio da imposição de violência para que as coisas sejam destituídas de sua aparência, e não através de decifrações ou atribuição de significações precipitadas. Por fim, a última estratégia é designada de princípio de exterioridade, que indaga as condições exteriores que possibilitam os discursos pela análise do próprio discurso, isto é, considerando a sua 
aparição e a sua regularidade para estabelecer séries diversas que delimitam as fronteiras dos acontecimentos.

Foucault menciona que em relação à história contemporânea há uma tendência de defini-la como propiciadora de períodos de longa duração, ou ainda, que despreza os acontecimentos singulares. No entanto, esse alcance secular somente é possível perante a preocupação em analisar os acontecimentos de modo minucioso, para a partir deles conseguir estabelecer as séries, a regularidades entre os fenômenos, assim como a emergência dos acontecimentos: "Certamente a história há muito tempo não procura mais compreender os acontecimentos por um jogo de causas e efeitos na unidade informe de um grande devir, vagamente homogêneo ou rigidamente hierarquizado" (FOUCAULT, 2012a, p. 53). Apesar da sofisticação desse modo de análise, surgem problemas quanto ao estatuto das noções de acontecimentos e descontinuidade. No caso do termo acontecimento, a noção mais apropriada, segundo Foucault, é “[...] à primeira vista, de um materialismo do incorporal" (FOUCAULT, 2012a, p. 54); por conseguinte, o termo descontínuo é atribuído às séries homogêneas resultantes dos acontecimentos que não possuem a necessidade de se vincularem com as demais séries: “[...] trata-se de cesuras que rompem o instante e dispersam o sujeito em uma pluralidade de posições e de funções possíveis" (FOUCAULT, 2012a, p. 55). Desse modo, enquanto a história das ideias busca evidenciar as representações ocultas dos discursos, a história dos sistemas de pensamento possibilita inserção de outras noções no pensamento, como por exemplo, o acaso, o descontínuo e a materialidade, que permitem pensar o discurso no contexto de sua realidade.

Nessa perspectiva, a análise foucaultiana se orienta de modo binário através do conjunto crítico e do conjunto genealógico, que diferem apenas no modo de conduzir a análise discursiva: "Entre o empreendimento crítico e o empreendimento genealógico, a diferença não é tanto de objeto ou de domínio mas, sim, de ponto de ataque, de perspectiva e de delimitação" (FOUCAULT, 2012a, p. 62-63). O conjunto crítico atua colocando em ação a teoria proposta pelo princípio de inversão (rarefação), que analisa o campo de apropriação e unificação discursiva (exclusões e limitações). Para Foucault o aspecto crítico conduziu as suas pesquisas em três momentos. Primeiramente contribuiu para analisar as funções de exclusões, por exemplo, a dicotomia entre razão e loucura. Na sequência, a análise das interdições que perpassam a noção de sexualidade e como ela se tornou objeto médico. E posteriormente a análise da vontade de verdade através de duas vias: na primeira, Foucault descreve a trajetória da escolha da verdade no contexto sofista, socrático e platônico, no qual 
surge a cisão entre o discurso verdadeiro e o falso, no contexto Clássico, no qual surge uma vontade de saber, e no contexto Moderno, no qual se edifica a ciência moderna; na segunda via, a vontade de verdade é analisada enquanto discurso que visa a um alcance científico, por exemplo, a análise das influências científicas no sistema penal. Segundo Foucault, a análise crítica também possibilita abordar outros contextos discursivos, como os procedimentos de limitação discursiva, e, por exemplo, realizar um estudo sobre a história da medicina, tendo como fio condutor o processo de elaboração do discurso médico (função do princípio do autor, comentário e disciplina) e não apenas descobertas ou conceitos, ou ainda, analisar as limitações no contexto literário ou filosófico. Já o conjunto genealógico é mais abrangente, no sentido que age com base nos princípios restantes, sendo a noção de descontinuidade a responsável por elucidar a formação discursiva seriada; a de especificidade, por tornar possíveis as normas específicas; e a de exterioridade, por apontar como os discursos apareceram, se desenvolveram e variaram. Sendo assim, "a crítica analisa os processos de rarefação, mas também de reagrupamento e de unificação dos discursos; a genealogia estuda sua formação ao mesmo tempo dispersa, descontínua e regular" (FOUCAULT, 2012a, p. 6162). Para Foucault, há uma relação de complementação entre ambos os tipos de descrições, que possibilita desvincular o discurso da análise do significante, na medida em que a descrição crítica detecta a rarefação do discurso através de uma desenvoltura aplicada (apropriações, exclusões e limitações discursivas), e a descrição genealógica investiga a formação de positividades (domínios de objetos), analisando o poder de afirmar ou negar as proposições: "Rarefação e afirmação, rarefação, enfim, da afirmação e não generosidade contínua do sentido, e não monarquia do significante"6 (FOUCAULT, 2012a, p. 66). Em suma, Foucault ressalta que a ordem do discurso, não resulta da revelação de um sentido oculto, mas de um amplo processo de elaboração discursiva, através da imposição de rarefações e afirmações.

\section{Referências bibliográficas}

DIDIER, Eribon. Michel Foucault uma Biografia. Trad. Hildegard Feist. - São Paulo: Companhia das letras, 1990.

\footnotetext{
${ }^{6}$ Nesse sentido: "Não há, pois, no conhecimento, uma adequação ao objeto, uma relação de assimilação, mas, antes, uma relação de distância e de dominação; não há, no conhecimento, algo como felicidade e amor, mas ódio e hostilidade; não há unificação, mas sistema precário de poder" (FOUCAULT, 2014, p. 142).
} 
FOUCAULT, Michel. A ordem do discurso. Trad. Laura Fraga de Almeida Sampaio. - 22. ed. - São Paulo: Edições Loyola, 2012a.

Ditos e escritos VIII. Segurança, penalidade e prisão. MOTTA, M. B. (org.). Trad. Vera Lucia Avelar Ribeiro. - 1. ed. - Rio de Janeiro: Forense Universitária, 2012b. Ditos e escritos X. Filosofia, diagnóstico do presente e verdade. MOTTA, M. B. (org.). Trad. Abner Chiquieri. - 1. ed. - Rio de Janeiro: Forense Universitária, 2014. 